\title{
Granule for Reconstitution Dosage Form
}

National Cancer Institute

\section{Source}

National Cancer Institute. Granule for Reconstitution Dosage Form. NCI Thesaurus.

Code C69066.

A solid in the shape of a small particle or grain mixed with a liquid to form a solution or suspension before administration. 